\title{
Nutrição nitrogenada de bromélias ${ }^{(1)}$
}

\author{
FERNANDA HELENA DE SOUZA SANTOS ${ }^{(2)}$; ELKA FABIANA APARECIDA ALMEIDA ${ }^{(3)}$; \\ JUSSARA ELLEN MORAES FRAZÃO(4); APARECIDA CÉLIA PAULA DOS SANTOS ${ }^{(5)}$
}

\section{RESUMO}

\begin{abstract}
As plantas da família Bromeliaceae destacam-se por suas cores e formas exóticas. Nos últimos anos, as bromélias têm apresentado grande importância econômica, com sua utilização em projetos paisagísticos e para decoração, sendo bastante cultivadas comercialmente. A adubação correta é um importante manejo para produção eficiente de plantas de melhor qualidade. Em decorrência disso, objetivou-se neste trabalho compilar informações acerca da nutrição nitrogenada de bromélias. Por exibirem diversos hábitos de crescimento, as bromélias estão expostas a diferentes fontes de abastecimento e formas nitrogenadas dependendo do ambiente em que se desenvolvem. Estudos comprovam que as bromélias epífitas exibem uma preferência pela forma nitrogenada orgânica e as bromélias terrestres, pela forma inorgânica devido à disponibilidade deste nutriente no meio. As bromélias exibem ainda adaptações morfológicas e fisiológicas específicas para aumentar a eficiência na absorção e assimilação de nitrogênio.
\end{abstract}

Palavras-chave: Bromeliaceae, nitrogênio, floricultura.

\section{ABSTRACT \\ Nitrogen nutrition of bromeliads}

Plants of Bromeliaceae family are noted for their exotics colors and shapes. In last years bromeliads have presented great economic importance, due its use in landscaping projects and for decoration, being quite grown commercially. Proper fertilizer is an important management for efficient production of plants with better quality. As a result, this study aimed to compile information about nitrogen nutrition of bromeliads. Due to the several growth habits, the bromeliads are exposed to different sources and forms of nitrogen supply depending on the environment in which they develop. Studies prove that the epiphytic bromeliads exhibit a preference for organic nitrogen form and terrestrial bromeliads by inorganic form due to the availability of this nutrient in the environment. Bromeliads also exhibit specific physiological and morphological adaptations to increase the uptake an assimilation of nitrogen.

Keywords: Bromeliaceae, nitrogen, floriculture.

\section{INTRODUÇÃO}

A família Bromeliaceae possui plantas com formas exóticas e grande diversidade de cores e variedade de inflorescências. Estes vegetais podem ser encontrados em diferentes condições ambientais desde o nível do mar e altitudes acima de $3.000 \mathrm{~m}$, tanto em regiões secas e quentes, quanto em regiões frias. Podem crescer em locais sombrios e frios como o interior das matas, ou em locais muito ensolarados, como em rochas à beira-mar, tudo isso em razão de sua facilidade de adaptação e especialização (PAULA e SILVA, 2000).

No Brasil, é possível encontrar plantas da família Bromeliaceae desde a Floresta Amazônica até as matas gaúchas. Existem cerca de 3.000 espécies nas Américas, das quais aproximadamente 1.200 são endêmicas ou típicas apenas do território brasileiro, sendo a Floresta Atlântica um dos principais centros de diversidade de espécies (LEME, 1999 citado por ARANDA-FRANCO, 2003).

As bromélias exibem morfologia e fisiologia diversificadas, o que favorece sua ocorrência em diferentes tipos de habitats (NIEVOLA et al., 2001). Assim sendo, sua nutrição na natureza é fortemente influenciada pelo seu hábito de crescimento que pode ser rupícola, saxícola, terrestre ou epífita.

As bromélias rupestres, como as do gênero Alcantarea, se prendem diretamente a rochas. As saxícolas desenvolvem-se nas fendas das pedras, onde há o acúmulo de matéria orgânica e material oriundo da rocha em decomposição (PAULA, 2005). Já as bromélias de hábito terrestre como as dos gêneros Ananas e Pitcairnia se desenvolvem diretamente na terra e absorvem os nutrientes do solo através de raízes bem desenvolvidas (BENZING e RENFROW, 1974). As bromélias epífitas como as do gênero Vriesea, Aechmea, Neoregelia e Guzmania apresentam estratégias nutricionais muito mais especializadas que as representantes dos grupos terrestres e rupestres. Elas crescem sobre troncos e ramos de outras plantas, utilizando-as somente para sustentação, não afetando seu sistema vascular e realizando fotossíntese para sintetizar seu próprio alimento. Além disso, constituem um grupo com total independência de nutrição do solo e crescem em locais altos em busca da luz do sol (BENZING e RENFROW, 1974).

\footnotetext{
(1) Recebido em 07/08/2010 e aceito para publicação em 09/03/2012.

${ }^{(2)}$ Mestranda pela Universidade Federal de Lavras, Departamento de Ciência do Solo, CP.3037, MG, Brasil. Email: nandahelena87@yahoo.com.br.* Autor para correspondência

${ }^{(3)}$ Pesquisadora Dra., Empresa de Pesquisa Agropecuária de Minas Gerais (EPAMIG). Rodovia BR 494, Km 02, Colônia de Bengo, CTAN, São João Del Rei, MG, Brasil, CEP 36301-360, Bolsista Fapemig.


CTAN, São João Del Rei, MG, Brasil, CEP 36301-360.

${ }^{(5)}$ Professora Dra., Universidade Federal de São João Del Rei, Campus Dom Bosco, CEP 36300-360, São João Del Rei, MG, Brasil.
} 
As bromélias epífitas obtêm água da umidade do ar do dossel, assim como diretamente da chuva, e obtêm os minerais da poeira e das superfícies das plantas sobre as quais crescem (RAVEN et al., 2001). O sistema radicular é bastante reduzido, e sua principal função é a fixação na planta hospedeira. Essas plantas podem possuir um agrupamento de folhas formando um reservatório denominado roseta, cisterna ou tanque, que, em geral, permite o acúmulo da água de chuva ou irrigação. Nesse caso, são denominadas epífitas com tanque e seus nutrientes são retirados do material orgânico armazenado na roseta da planta (PAULA e SILVA, 2000).

As espécies epífitas da subfamília Tillandsioideae são chamadas de "atmosféricas" em função de retirarem do ar seus nutrientes, seja pela deposição úmida ou seca (LEME, 1993). A nutrição das bromélias epífitas dotadas de tanque é muito efetiva em locais úmidos, enquanto as formas atmosféricas são adaptadas a ambientes mais secos e menos férteis. Desta forma, as duas características morfológicas, como a ocorrência de folhas formando uma roseta e a presença de tricomas absorventes, são excepcionalmente importantes para designar o epifitismo nesta família, que, em associação, caracteriza a especialização nutricional desse grupo (BENZING e RENFROW, 1974).

Pela sua valorização na floricultura e paisagismo resultando na maior procura dessas plantas para ornamentação, muitas espécies de bromélias encontradas no comércio atualmente são provenientes do extrativismo predatório, processo que as tornou vulneráveis à extinção (SANTOS et al., 2006).

Em função da demanda cada vez mais crescente dessas plantas para a comercialização, deve-se considerar que o cultivo de bromélias em grande escala por produtores pode trazer vários benefícios, entre eles a redução do custo de produção, do preço final e principalmente a diminuição do extrativismo predatório das bromélias nativas, permitindo a conservação delas em seu ambiente natural (ANDRADE e DEMATTÊ, 1999).

A produção de bromélias para fins comerciais é recente no meio agrícola, carecendo de informações técnicas que possam promover o aumento da produtividade e melhoria na qualidade das plantas. Para fins comerciais, as bromélias são mais bem cultivadas em condições que simulem seu habitat natural, pois quando se desenvolvem em ambiente adequado, requerem pouca manutenção (BRICKELL, 1996).

Em cultivo comercial, o fornecimento de nutrientes, especialmente o nitrogênio $(\mathrm{N})$, contribui, de forma significativa, tanto no aumento da produtividade como no aumento do custo da produção. Nesta situação, a otimização da eficiência nutricional é fundamental para ampliar a produtividade e reduzir o custo de produção (FAGERIA, 1998).

O $\mathrm{N}$ destaca-se dos demais nutrientes por ser o elemento mineral requerido em maior quantidade pelas plantas e juntamente com o $\mathrm{P}, \mathrm{K}, \mathrm{Ca}, \mathrm{Mg}$ e $\mathrm{S}$ são denominados macronutrientes. É um importante elemento para o crescimento e desenvolvimento das plantas porque faz parte da composição de proteínas, ácidos nucleicos e muitos outros constituintes celulares importantes, incluindo membranas e diversos hormônios vegetais (MARSCHNER, 1995). Além disso, o $\mathrm{N}$ interfere diretamente no processo fotossintético pela sua participação na molécula de clorofila (ANDRADE et al., 2003).

As bromélias, por apresentarem diversos hábitos de crescimento, exibem adaptações morfológicas e fisiológicas específicas para a utilização de N. A absorção desse nutriente tem sido estudada em muitas plantas, entretanto, para bromélias, as informações ainda são incipientes (NIEVOLA et al., 2001).

Considerando-se os fatores acima mencionados, o objetivo deste trabalho foi compilar informações acerca da nutrição nitrogenada das bromélias.

\section{BROMÉLIAS E A RESPOSTA AO NITROGÊNIO}

Em razão de as bromélias exibirem diversos hábitos de crescimento, elas também estão expostas a diferentes fontes de abastecimento e formas nitrogenadas, incluindo a forma mineral e orgânica (NIEVOLA et al., 2001).

O desenvolvimento de bromélias é em grande parte dependente da nutrição nitrogenada. Em estudo realizado por ENDRES e MERCIER (2001a), bromélias cultivadas in vitro reagiram significativamente ao aumento da concentração de nitrogênio na cultura. Conforme a Figura 1, observou-se que a massa seca acumulada em Ananas comosus alcançou o máximo com a concentração de $10 \mathrm{mM}$ de $\mathrm{N}$, tendo sofrido subsequente diminuição e estabilização, quando nutridas com amônio e a ureia.



Figura 1. Massa seca acumulada de brotos de Ananas comosus e Vriesea gigantea cultivadas in vitro por dois meses com concentração equimolar de nitrogênio usando como fonte nitrogenada, ureia ou $\left(\mathrm{NH}_{4}\right)_{2} \mathrm{SO}_{4}$ (ENDRES e MERCIER, 2001b).

Figure 1. Dry matter accumulation of the shoot of Ananas comosus and Vriesea gigantea cultivated for two months in vitro with equimolar nitrogen concentrations in the form of urea or $\left(\mathrm{NH}_{4}\right)_{2} \mathrm{SO}_{4}$. 
As plantas terrestres, incluindo as bromélias, obtêm $\mathrm{N}$ principalmente pela sua absorção na solução do solo, por meio de suas raízes, que são bastante desenvolvidas (MARSCHNER, 1995).

Por outro lado, as epífitas podem obter $\mathrm{N}$ da atmosfera, uma vez que, durante os momentos de chuva, os íons e aminoácidos presentes nos troncos e folhas da planta hospedeira são levados pela água da chuva até suas folhas e interior das cisternas (BENZING, 1973).

\section{ADAPTAÇÕES MORFOLÓGICAS E A FORMA NITROGENADA DE ABSORÇÃO FOLIAR EM BROMÉLIAS EPÍFITAS}

Assim como relatado por MALAVOLTA (1981), a vida vegetal teve início na água. Neste período, o órgão responsável pela fotossíntese, a folha, era também incumbido de absorver a água e os nutrientes. Quando os vegetais passaram para a vida terrestre, desenvolveu-se a especialização de funções, ficando as folhas responsáveis por produzir carboidratos e as raízes, por fixar a planta e absorver a água e minerais. No entanto, a folha não perdeu a capacidade primitiva de absorver água e minerais. Desta forma, é possível fornecer nutrientes para as plantas via foliar (ZAMBOLIM, 2000).

As bromélias epífitas possuem propriedades particulares em relação à sua nutrição, que, em função de não terem conexão direta com o banco de nutrientes do solo florestal, são dependentes de atributos fisiológicos e morfológicos (tricomas e tanques armazenadores), que lhes garantem a sobrevivência nas copas das árvores (LEME, 1993).

As folhas das bromélias são, em maior ou menor escala, recobertas por diminutos tricomas ou escamas (PAULA e SILVA, 2000). Os tricomas são apêndices de origem epidérmica, presentes em qualquer órgão vegetal, de forma permanente ou passageira.

Em bromélias epífitas, os tricomas são classificados como tectores ou não-glandulares e apresentam forma escamiforme, tendo a função de aumentar a reflectância da radiação luminosa e contribuir para absorção de água e sais minerais. As escamas associadas à roseta lhes permitem ainda se adaptar a ambientes extremamente desfavoráveis a outras plantas (PAULA e SILVA, 2000). Estas escamas foliares desempenham importante função na proteção contra a dessecação em ambientes com restrição hídrica porque diminuem tanto a temperatura da folha como a transpiração e, desta forma, minimizam a perda de água (MOREIRA et al., 2005). Além disso, as escamas protegem a planta de predadores e atraem polinizadores e dispersores por formarem denso indumento sobre inflorescências e frutos, refletindo luz e secretando enzimas digestivas (BENZING, 2000).

Devido a estas especialidades, as bromélias têm excepcional capacidade de absorver nutrientes por meio de suas folhas. Estudos puderam comprovar a importância da adubação nitrogenada foliar em bromélias (DEMATTÊ, 2006). FERREIRA et al. (2007) observaram que a utilização de ureia como fonte nitrogenada foliar proporcionou aumento linear da altura média das plantas quando submetidas a concentrações crescentes dessa fonte nitrogenada.

A adubação foliar é o processo em que a nutrição das plantas é feita pela parte aérea, principalmente, das folhas. Em culturas de alto rendimento e ciclo curto como a floricultura, admite-se o fornecimento dos macronutrientes, incluindo o N, totalmente via foliar, como substituto da via radicular (FAQUIN, 2001).

A ureia é indicada para adubação foliar por conter alto teor de N, alto grau de solubilidade e baixa corrosividade. $\mathrm{O}$ risco de causar injúrias nas folhas é menor para a ureia em relação às outras fontes de $\mathrm{N}$, se comparadas soluções com concentrações equivalentes (NETO et al., 2001).

Argumenta-se que a aplicação foliar é um meio eficiente de nutrir os vegetais em $\mathrm{N}$ e a ureia auxiliaria a absorção dos micronutrientes contidos na solução aplicada nas folhas, resultando em maior desenvolvimento e produtividade das plantas. Entretanto, pouco se conhece sobre a aplicação de ureia via foliar como fonte isolada de $\mathrm{N}$ durante o estádio vegetativo de bromélias (BOARETTO et al., 1999).

Em função de a absorção de água e nutrientes da atmosfera ser feita quase totalmente pelas folhas especializadas com tricomas, é preciso cuidado especial quando se aplicam fertilizantes em bromélias, pois elas são extremamente sensíveis ao excesso de nutrientes (DEMATTÊ, 2006).

\section{METABOLISMO DO NITROGÊNIO NAS PLANTAS}

As fontes de $\mathrm{N}$ estão disponíveis para as plantas nas formas de nitrato $\left(\mathrm{NO}_{3}^{-}\right)$, amônio $\left(\mathrm{NH}_{4}^{+}\right)$(consideradas as formas preferenciais de absorção) ou nitrogênio atmosférico $\left(\mathrm{N}_{2}\right)$ (CORDEIRO, 2004).

As plantas assimilam a maioria do nitrato absorvido por suas raízes em compostos orgânicos nitrogenados. A redução do $\mathrm{NO}_{3}{ }^{-}$é um processo que ocorre em duas etapas. $\mathrm{Na}$ primeira delas, catalisada pela nitrato redutase (NR), o $\mathrm{NO}_{3}$-é reduzido a nitrito $\left(\mathrm{NO}_{2}^{-}\right)$com o consumo de elétrons. A fonte de poder redutor para a NR pode ser o NADH ou $\mathrm{NAD}(\mathrm{P}) \mathrm{H}$, dependendo da isoenzima. Na segunda etapa, a nitrito redutase $(\mathrm{NiR})$ catalisa a redução $\mathrm{NO}_{2}^{-}$a $\mathrm{NH}_{4}^{+}$ com um gasto de 6 elétrons fornecidos pela ferredoxina

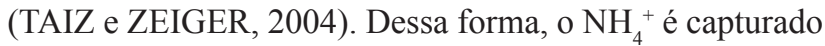
pela planta do meio externo ou obtido como resultado da fotorrespiração e incorporado na forma de aminoácidos pela ação da glutamina sintetase (GS) ou da glutamato sintetase (GOGAT) (SOUZA e FERNANDES, 2006).

Uma forma de analisar alguns aspectos do metabolismo do $\mathrm{N}$ nas plantas é comparando as atividades de enzimas que catalisam reações de conversão de formas nitrogenadas.

NIEVOLA et al. (2001), em estudos com bromélias, compararam as atividades das enzimas no metabolismo do nitrogênio (NR e GS) entre Vriesea fosteriana, espécie saxícola com tanque, e Tillandsia pohliana, espécie epífita atmosférica, fornecendo $\mathrm{NO}^{3-}, \mathrm{NH}^{4+}$ e $\mathrm{NH}_{4} \mathrm{NO}_{3}$ (nitrato de amônio) como fontes nitrogenadas. Seus estudos concluíram que as espécies que formam tanque apresentaram atividade GS mais elevada que em T. pohliana. A baixa atividade da GS encontrada em $T$. pohliana pode estar relacionada aos distintos caminhos fotossintéticos e pode, além disso, 
refletir uma adaptação para a sobrevivência a um ambiente com limitação nutricional. Os autores concluíram que a aplicação do nitrato foi fonte ineficiente de $\mathrm{N}$ para suportar o crescimento de ambas as espécies, porém foi uma fonte efetiva quando oferecida juntamente com $\mathrm{NH}^{4+}$.

\section{ASSIMILAÇÃO DE NITROGÊNIO EM DIFERENTES PORÇÕES FOLIARES}

O estudo da estrutura foliar das Bromeliaceae pode ser uma ótima ferramenta para aprofundar os conhecimentos da fisiologia da nutrição dessas plantas, especialmente em relação à estrutura das escamas foliares e dos estômatos (PROENÇA e SAJO, 2007).

TAKAHASHI (2011) desenvolveu um trabalho cujo objetivo foi verificar possíveis diferenças quanto à capacidade de assimilação do $\mathrm{N}$ em diferentes porções foliares de espécie de bromélia epífita com tanque (Vriesea gigantea). Neste estudo, foi possível observar aumentos das atividades da nitrato redutase (NR) e urease apenas na porção basal, e as maiores atividades de glutamina sintetase (GS) e glutamato desidrogenase (GDH) foram detectadas principalmente na porção apical das folhas em resposta ao fornecimento $\mathrm{NO}^{3-} / \mathrm{NH}^{4+}(3: 2)$ ou ureia. Assim, a região apical pode estar envolvida, preferencialmente, com a assimilação de $\mathrm{N}$ na forma amoniacal, enquanto a região basal, com a absorção de compostos nitrogenados, redução do nitrato e hidrólise da ureia, caracterizando, assim, uma divisão espacial das funções.

Esse resultado provavelmente estaria relacionado à exposição das porções das folhas. A porção da base da folha, que forma o tanque da planta, estaria em maior contato com a água e os nutrientes ali acumulados e desta forma mais propícia à absorção do N. Já a porção apical, que é mais exposta à luz, estaria relacionada a uma taxa fotossintética mais elevada em que a atividade das enzimas do metabolismo do $\mathrm{N}$ também são mais intensas. Esse resultado pôde ser verificado através da enzima GS, que permitiu maior síntese de aminoácidos e consequentemente de proteínas necessárias à manutenção dos metabólitos das plantas como a fotossíntese. Assim, a determinação da densidade dos estômatos é interessante, uma vez que são responsáveis pela regulação das trocas gasosas, influenciando diretamente a fotossíntese (RAVEN, 2001).

Atualmente, pouco se conhece acerca dos mecanismos que regulam a penetração dos íons através dos estômatos. Segundo ROSOLEM (2002), apenas uma pequena proporção dos estômatos (menos de 10\%) participa ativamente da absorção, mas, mesmo assim, a absorção está estreitamente correlacionada com o número de estômatos presentes. TAKAHASHI (2007), considerando a hipótese de divisão de função em diferentes partes da folha de uma bromélia epífita, observou correlação inversa entre as densidades de tricomas e estômatos e as duas porções foliares, existindo um gradiente de aumento de tricomas e diminuição de estômatos do ápice para a base.

Segundo BENZING e RENFROW (1974), os tricomas destinados à absorção de nutrientes presentes nas espécies atmosféricas são cerca de 5\% mais abundantes que em outros grupos de bromélias. Ao contrário, bromélias terrestres e com tanque possuem tricomas mais espaçados e não mais que $1 \%$ da superfície foliar das Bromelioideae e Pitcairnioideae é ocupada por tricomas.

\section{FITOTELMAS E A DISPONIBILIDADE DE N}

Uma peculiaridade interessante é observada em bromélias formadoras de roseta. Suas folhas se agregam na base, formando estreitos tanques de água que, em algumas espécies, podem conter até 45 litros de água de chuva. Esses reservatórios de água são denominados fitotelmas, sendo constituídos de microcosmos de bactérias, protozoários, larvas, insetos, predadores de insetos, ácaros, anelídeos e anuros, além de vegetais em decomposição (RAVEN, 2001 e SOPHIA, 1999).

Nesse ambiente, formigas que vivem em associação com algumas bromélias depositam outros insetos, capturados por elas, no interior da cavidade das cisternas. Esses detritos de animais e a própria excreta das formigas enriquecem o tanque de nutrientes. As epífitas com tanque também têm associações com uma extensa microflora, diversos invertebrados e vertebrados que geralmente procuram essas plantas como local de proteção, alimentação e/ou reprodução. Essas associações possibilitam aumento na disponibilidade de fontes nitrogenadas inorgânicas como amônio, secretado por cianobactérias, ou orgânicos, como a ureia, excretados pelos anfíbios viventes em bromélias com tanque (BENZING, 1990 e 2000).

A disponibilidade de $\mathrm{N}$ e de outros nutrientes minerais no tanque das bromélias Catopsis floribunda e Guzmania monostachia foi observada no sul da Flórida (Tabela 1). Em ambas as espécies, foram encontradas consideráveis quantidades de $\mathrm{N}$ em seu tanque.

Em função da diversidade de fontes nitrogenadas encontrados no fitotelma, o $\mathrm{N}$ é disposto em diferentes componentes, sendo facilmente disponível na forma inorgânica como o $\mathrm{NH}^{4+}$ e o $\mathrm{NO}^{3-}$, bem como em substâncias de baixo peso molecular como a ureia e aminoácidos e em substâncias de alto peso molecular como as proteínas. Porém, as plantas apresentam preferências quanto à forma nitrogenada absorvida (INSELSBACHER et al., 2007).

\section{ABSORÇÃO PREFERENCIAL DE N QUANTO À FORMA ORGÂNICA OU INORGÂNICA}

Certos estudos demonstraram que a forma nitrogenada orgânica elevou a produção da biomassa das bromélias comparada com a forma nitrogenada inorgânica. NIEVOLA et al. (2001) obtiveram resultados que comprovam alta produção de biomassa em espécie de bromélia com tanque (Vriesea gigantea), cultivada in vitro, quando suprida com ureia, enquanto seu crescimento com o fornecimento de $\mathrm{NO}^{3-}$ foi significativamente menor. Segundo INSELSBACHER (2007), isso pode ser ecologicamente importante uma vez que a ureia ou 
Tabela 1. Teor de nutrientes no conteúdo líquido e sólido de três tanques de mudas de bromélias Table 1. Total quantities of nutrients in liquid and debris impounded by three rosets each of bromeliads seedlings

\begin{tabular}{lcccccc}
\multicolumn{1}{c}{ Espécies } & \multicolumn{7}{c}{ Teor $(\mathbf{m g} / \mathbf{g})$} \\
& Ca & $\mathbf{K}$ & $\mathbf{M g}$ & $\mathbf{N}$ & $\mathbf{N a}$ & $\mathbf{P}$ \\
Catopsis floribunda & 13.3 & 0.55 & 0.62 & 14.4 & 0.30 & 0.77 \\
& 13.3 & 0.57 & 1.07 & 22.1 & 0.21 & 0.95 \\
& 13.8 & 0.28 & 0.81 & 18.7 & 0.22 & 0.78 \\
\hline \multirow{2}{*}{ Guzmania monostachia } & 18.3 & 0.60 & 0.80 & 12.6 & 0.27 & 0.74 \\
& 10.1 & 0.43 & 0.46 & 15.7 & 0.16 & 0.71 \\
& 13.0 & 3.01 & 1.17 & 14.2 & 0.76 & 0.64 \\
\hline
\end{tabular}

Fonte: BENZING e RENFROW, 1974.

o ácido úrico pode ser secretado por anfíbios ou outros pequenos animais que habitam o tanque das bromélias.

ENDRES e MERCIER (2001a) constataram que a espécie de bromélia terrestre Ananas comosus mostrou preferência pela forma inorgânica nitrogenada em elevadas concentrações, enquanto a espécie epífita Vriesea gigantea obteve melhor desenvolvimento com $\mathrm{N}$ orgânico em níveis relativamente baixos. Segundo os autores, isso reflete a adaptação das bromélias ao ambiente em que o N presente no solo pode ser relativamente mais abundante que no ambiente epífito. Por outro lado, a espécie epífita V. gigantea pode estar exposta a uma constante deficiência nutricional em seu habitat natural, apresentando maior eficiência na absorção de $\mathrm{N}$, atingindo potencial máximo de crescimento com baixas taxas de $\mathrm{N}$.

NIEVOLA et al., (2001) sugerem que espécies de bromélias epífitas com tanque aumentaram sua biomassa quando supridas com N orgânico como a ureia. Apesar disso, INSELBACHER (2007), avaliando a atividade microbiana e a absorção foliar de $\mathrm{N}$ na bromélia Vriesea gigantea, concluiu que essa espécie absorve ambas as formas nitrogenadas, orgânica e inorgânica, com uma clara preferência para $\mathrm{NH}^{4+}$.

INSELSBACHER (2007), estudando a atividade enzimática, a taxa bruta de transformação nitrogenada e a taxa de absorção foliar no tanque de Vriesea gigantea, verificou que a maior taxa de absorção de $\mathrm{N}$ é na forma de $\mathrm{NH}^{4+}$, seguida de $\mathrm{NO}^{3-}$, depois ureia e baixas taxas de aminoácidos. Segundo o autor, isso se deve principalmente à alta atividade da deaminase, uma enzima produzida por organismos microbianos que mineralizam rapidamente os aminoácidos em $\mathrm{NH}^{4+}$. Em contraste, o $\mathrm{NO}^{3-}$, forma nitrogenada preferencial de absorção de plantas terrestres, parece ter papel secundário na nutrição nitrogenada de Vriesea gigantea.

Vários estudos já mostraram que as bromélias formadoras de tanque são as mais tolerantes ao cultivo em amônio, uma vez que apresentaram maior preferência pela forma amoniacal em comparação com a forma nítrica como fonte de $\mathrm{N}$ inorgânico. Essa capacidade de transportar o amônio pode ser uma característica que as bromélias epífitas adquiriram com a evolução, já que o amônio parece ser a fonte nitrogenada mais disponível em relação ao nitrato no meio epífito (TAKAHASHI et al., 2007).

\section{IMPLICAÇÕES DA LIMITAÇÃO NUTRICIONAL DE BROMÉLIAS}

Diversos fatores são requeridos para o crescimento das plantas tais como, luz $\mathrm{CO}_{2}$, água e nutrientes. Entre esses fatores, os nutrientes minerais merecem especial destaque, já que, atuando como íons, moléculas, ou incorporados a estruturas celulares, regulam os processos metabólicos das plantas, sendo essenciais ao ciclo vital (MARSCHNER, 1995). Havendo limitações na disponibilidade de um dos elementos essenciais às plantas, desarranjos nos processos metabólicos e, consequentemente, queda na produtividade e qualidade dos vegetais são passíveis de ocorrer (EPSTEIN e BLOOM, 2006).

No entanto, as plantas da família Bromeliaceae apresentam características específicas que as tornam aptas a sobreviver sob ambientes com limitações nutricionais.

ENDRES e MERCIER (2001b) observaram que a espécie Vriesea gigantea (bromélia epífita com tanque) é mais tolerantes à escassez de $\mathrm{N}$ quando comparada à espécie Ananas comosus (bromélias terrestres). Isso pode ser reflexo da adaptação das bromélias ao ambiente terrestre, onde o $\mathrm{N}$ pode ser relativamente mais abundante que em epífitas. Por outro lado, as espécies epífitas podem estar expostas a constante estresse nutricional em seu habitat natural, causando maior eficiência na absorção de nitrogênio, estendendo ao máximo seu potencial de crescimento com baixos níveis de $\mathrm{N}$.

BENZING e RENFROW (1974) compilaram na Tabela 2 o teor de alguns nutrientes encontrados no tecido de espécies de bromélias localizadas no campo com representantes de três estratégias nutricionais. Observouse que as bromélias atmosféricas (Tillandsias) requerem poucas quantidades de $\mathrm{K}, \mathrm{Pe} \mathrm{N}$ por unidade de tecido foliar comparado com as plantas que possuem outros hábitos de crescimento, refletindo as condições de seu habitat.

BENZING (1983) observou que a aplicação de fertilizantes não promoveu crescimento de bromélias atmosféricas cultivadas em estufa. Ele concluiu que, embora a maioria das plantas terrestres sejam adaptadas a solos férteis, as plantas epífitas têm capacidade limitada para se desenvolver em resposta a nutrientes que lhe são oferecidos e que o menor nível de crescimento dessas plantas é uma adaptação para sobreviver em ambiente oligotrófico. 
Tabela 2. Composição dos elementos (\%) no tecido foliar de espécies representando as três estratégias nutricionais nas Bromeliaceae

Table 2. Elemental composition (\%) of leaf blade tissues representing all three nutrition strategies in Bromeliaceae

\begin{tabular}{|c|c|c|c|c|c|c|c|}
\hline $\begin{array}{c}\text { Estratégia ecológica } \\
\text { e espécies }\end{array}$ & Subfamília & $\mathrm{Ca}$ & $\mathbf{K}$ & Mg & $\mathbf{N}$ & $\mathbf{N a}$ & $\mathbf{P}$ \\
\hline \multicolumn{8}{|l|}{ Terrestres } \\
\hline Bromelia karatas & Bromelioideae & 1.19 & 2.48 & 0.14 & 0.67 & 0.064 & 0.068 \\
\hline Pitcairnia bromeliafolia & Pitcairnioideae & 1.06 & 1.02 & 0.14 & 1.37 & 0.036 & 0.084 \\
\hline Pitcairnia sp. & Pitcairnioideae & 0.26 & 1.70 & 0.18 & 0.81 & 0.0044 & 0.095 \\
\hline \multicolumn{8}{|l|}{ Epífitas com tanque } \\
\hline Aechmea nudicaulis & Bromelioideae & 0.38 & 1.94 & 0.20 & 0.57 & 0.18 & 0.057 \\
\hline A. paniculigera & Bromelioideae & 0.51 & 1.03 & 0.15 & 0.54 & 081 & 0.042 \\
\hline Catopsis berteroniana & Tillandsioideae & 0.40 & 0.72 & 0.12 & 1.14 & 0.55 & 0.085 \\
\hline C. floribunda & Tillandsioideae & 1.15 & 1.59 & 0.18 & 1.36 & 0.32 & 0.091 \\
\hline Guzmania lingulata & Tillandsioideae & 0.44 & 1.59 & 0.25 & 0.88 & 0.19 & 0.063 \\
\hline G. monostachia & Tillandsioideae & 0.34 & 1.94 & 0.14 & 0.60 & 0.10 & 0.075 \\
\hline Tillandsia anceps & Tillandsioideae & 0.39 & 1.06 & 0.14 & 0.85 & 0.26 & 0.044 \\
\hline Vriesea splendes & Tillandsioideae & 0.36 & 1.43 & 0.20 & 0.89 & 0.48 & 0.058 \\
\hline \multicolumn{8}{|l|}{ Epífita Atmosférica } \\
\hline T. balbisiana & Tillandsioideae & 0.83 & 0.34 & 0.14 & 0.36 & 0.41 & 0.035 \\
\hline T.circinata & Tillandsioideae & 0.73 & 0.32 & 0.14 & 0.34 & 0.65 & 0.029 \\
\hline T.pruinosa & Tillandsioideae & 0.70 & 0.48 & 0.24 & 0.73 & 0.38 & 0.060 \\
\hline T.usneoides & Tillandsioideae & 0.67 & 0.50 & 0.29 & 0.82 & 0.55 & 0.012 \\
\hline
\end{tabular}

Fonte: BENZING e RENFROW, 1974.

Bromélias atmosféricas maturam muito mais lentamente que as bromélias terrestres ou com tanque. As espécies de Tillandsias atmosféricas comumente requerem quatro anos ou mais para atingir a primeira floração a partir de sementes, enquanto as espécies terrestres e com tanque atingem o mesmo estágio de maturidade, muitas vezes o mesmo tamanho, na metade desse tempo. As aplicações aleatórias de fertilizantes, água e diferentes intensidades luminosas são efetuadas a fim de acelerar o crescimento dessas plantas em casa de vegetação ou estufa (BENZING e RENFROW, 1974).

\section{CONCLUSÃO}

Neste estudo, foi possível verificar a considerável diversidade ecológica das bromélias e sua particular adaptação aos diversos ambientes, com características morfológicas e fisiológicas únicas desse grupo. A nutrição nitrogenada adequada das bromélias é dependente do seu hábito de crescimento.

As bromélias epífitas exibem preferência pela forma nitrogenada orgânica e as bromélias terrestres, pela forma inorgânica por causa da disponibilidade deste nutriente no meio. Além disso, essas plantas exibem adaptações específicas para aumentar a eficiência na absorção e assimilação de N.

\section{AGRADECIMENTO}

À Fundação de Amparo à Pesquisa do Estado de Minas Gerais (Fapemig), pelo financiamento das bolsas de iniciação científica, pós-doutorado e incentivo à pesquisa.

\section{REFERÊNCIAS}

ANDRADE, F. S. A.; DEMATTÊ; M. E. S. P. Estudo sobre produção e comercialização de bromélias nas regiões sul e sudeste do Brasil. Revista Brasileira de Horticultura Ornamental, Campinas, v.5, n.2, p.97-110, 1999.

ANDRADE, A. C.; FONSECA, D. M.; QUEIROZ, D. S.; SALGADO, L. T.; CECON, P. R. Adubação nitrogenada e potássica em capim-elefante (Pennisetum purpureum schum. cv. napier). Ciência e Agrotecnologia, Lavras, p.1643-1651, 2003. Edição especial.

ARANDA-FRANCO, A. N.; BONASSA, R.C.; RODRIGUES, A. P. M. Influência do $\mathbf{G H}_{3}$ na germinação in vitro de cinco espécies de bromélias em perigo de extinção. In: CONGRESSO NACIONAL DE BOTÂNICA, Recife. PE. Horticultura Brasileira - Sociedade Brasileira de Olericultura. Recife, PE, 2003. v.21, p.294.

BENZING, D. H. Mineral nutrition and related phenomena in Bromeliaceae and Orchidaceae. Quarterly Review of Biology, v.48, n.2, p.277-290,1973.

BENZING, D. H. \& RENFROW, A. The mineral nutrition of Bromeliaceae. Botanical Gazette. v.135, n.4, p.281288, 1974.

BENZING, D. H. Vascular Epiphytes: A survey with special reference to their interactions with other organisms. In: Tropical Rain Forest: Ecology and Management; Sutton, S.L.; Whitmore, T.C.; Chadwick, A.C., Eds.; Blackwell Scientific Publication: Oxford, Eng., p.11-24, 1983. 474p. 
BENZING, D. H. Vascular epiphytes, general biology and related biota. Ashton, P.S. (ed), Cambridge: Cambridge University Press, 1990, 354p.

BENZING, D. H. Bromeliaceae: Profile of an Adaptive Radiation. Cambridge: University Press, Cambridge, 2000, 390p.

BOARETTO, A. E.; SANTOS NETO, P.; MUROAKA, T.; OLIVEIRA, M. W.; TRIVELIN, P. C. O. Fertilização foliar de nitrogênio para laranjeira em estágio de formação. Scientia Agricola. Piracicaba, v.56, n.3, p. 621-626, 1999.

BRICKELL, C. The Royal Horticultural Society A-Z Encyclopedia of Garden Plants. London, 1996. v.1, 576 p.

CORDEIRO, L. Fixação do Nitrogênio. In: Kerbauy, G. B. Fisiologia Vegetal. Primeira edição. Guanabara Koogan, Rio de Janeiro, 2004, 452p.

DEMATTÊ, M. E. S. P. Cultivo de Tillandsia kautskyi E. Pereira, bromélia brasileira em risco de extinção: considerações sobre adubação foliar. Revista Brasileira de Horticultura Ornamental. Campinas, v.12, n.2, p.112116, 2006.

ENDRES, L.; MERCIER, H. Influence of nitrogen forms on the growth and nitrogen metabolism of bromeliads. Journal of Plant Nutrition, v.24, n.1, p.29-42, 2001a.

ENDRES, L.; MERCIER, H. Ammonium and urea as nitrogen sources for bromeliads. Journal of Plant Physiology, v.158, n.22, p.205-212, 2001b.

FAGERIA, N. K. Otimização da eficiência nutricional na produção das culturas. Revista Brasileira de Engenharia Agrícola Ambiental. Campina Grande, v.2, p.6-16, 1998.

FAQUIN, V. Nutrição Mineral de Plantas. UFLA/ FAEPE, 2001. 182p. (Texto Acadêmico).

FERREIRA, C. A.; PAIVA, P. D. O; RODRIGUES, T. M. R.; RAMOS, D. P.; CARVALHO, J. G; PAIVA, R. Desenvolvimento de mudas de bromélia (Neoregelia cruenta (R. Graham) L. B. Smith) cultivadas em diferentes substratos e adubação foliar. Ciência e Agrotecnologia, v.31, n.3, 2007.

INSELSBACHER, E.; CAMBUI, C.A.; RICHTER, A.; STANGE, C. F.; MERCIER, H. Microbial activities and foliar uptake of nitrogen in the epiphytic bromeliad Vriesea gigantea. New Phytologist, v.175, p.311-320, 2007.

LEME, E. M. C. Bromélias na Natureza. Rio de Janeiro: Marigo Comunicação Visual, 1993.

LUTHER, H. E. An alphabetical list of Bromeliad binomials. 2000. Disponível em: http://www.selby.org/ research/bic/ Binom_2000_Alpha.pdf. Acesso em 03 de abr. 2009.
MALAVOLTA, E. Manual de química agrícola Adubos e adubações. 3.ed. São

Paulo: Editora Agronômica Ceres Ltda., 1981. 596p.

MARSCHNER, H. Mineral nutrition of highter plants. New York: Academic, 1995. 889p.

MOREIRA, B. A. CRUZ-BARROS, M. A. V.; WANDERLEY, M. G. L. Morfologia polínica de algumas espécies dos gêneros Neoregelia L. B. Sm. e Nidularium Lem. (Bromeliaceae) do Estado de São Paulo. Acta Botanica Brasílica. Brasil, 2005. v.19, n.1, p.61-70.

NETO, A. E. F.; VALE, F. R.; RESENDE, A. V.; GUILHERME, L. R. G.; GUEDES, G. A. A. Fertilidade do solo. Lavras: UFLA/FAEPE, 2001. 252p.

NIEVOLA, C. C.; MERCIER, H.; MAJEROWICZ, $\mathrm{N}$. Levels of nitrogen assimilation in bromeliads with different growth habitats. Journal of Plant Nutrition, v.24, n.9, p.1387-1398, 2001.

PAULA, C. C.; SILVA, H.M.P. Cultivo prático de bromélias, Viçosa-MG: UFV, 2000, p.116. 70p.

PAUlA, C. C. Cultivo de Bromélias. Informe Agropecuário - Floricultura, v.26, n. 227, p.73-84, 2005.

PROENÇA, S. L.; SAJO, M. G. Estrutura foliar de espécies de Aechmea Ruiz e Pav. (Bromeliaceae) do Estado de São Paulo. Acta Botanica Brasilica, Brasil, v.18, n.2, 2007.

RAVEN, P.H.; EVERT, R.F.; EICHHORN, S.E. Biologia vegetal. 6.ed. Rio de Janeiro: Guanabara Koogan, 2001, $906 \mathrm{p}$.

ROSOlEM, C. A. Recomendação e Aplicação de Nutriente Via Foliar. Lavras: Editora UFLA/FAEPE, 2002.

SANTOS, J. A. T.; MARQUES-SANCHES, A. M. M.; MONTANHER, D. R.; ORFRINI, A. C.; PUJALS, A.; SANTANA, T. F.; MILANEZE-GUTIERRE, M. A. O cultivo de orquídeas e bromélias como ferramenta para a preservação ambiental. In: IV FÓRUM DE EXTENSÃO E CULTURA DA UEM: PERSPECTIVAS DA EXTENSÃO UNIVERSITÁRIA E DA PRESTAÇÃO DE SERVIÇOS, 2006.

SOPHIA, M. G. Desmídias de Ambientes Fitotélmicos bromelícolas. Revista Brasileira de Biologia, v.59, n.1, p.141-150, 1999.

SOUZA, S. R.; FERNANDES, M. S. Nitrogênio. In: FERNANDES, M. S. (ed.). Nutrição Mineral de Plantas, Viçosa: SBCS, 2006. 432p.

TAIZ, L.; ZEIGER, E. Fisiologia vegetal. 3.ed. Porto Alegre: Artmed, 2004, 719 p. 
TAKAHASHI, C.A.; CECCANTINI, G. C. T.; MERCIER, H. Differential capacity of nitrogen assimilation between apical and basal leaf portions of a tank epiphytic bromeliad. Journal of Plant Physiology, vol.19, n.2, p.19-126, 2007.

TAKAHASHI, C. A.; MERCIER, H. Nitrogen metabolism in leaves of a tank epiphytic bromeliad: characterization of a spatial and functional division. Journal of Plant Physiology, v.168, n.11, p.1208-1216, 2011.

ZAMBOLIM, L. Café: produtividade, qualidade e sustentabilidade. Viçosa: UFV, 2000. 